\title{
Coordination of Nutrient Availability and Utilization by MAX- and MLX-Centered Transcription Networks
}

\author{
John M. O'Shea and Donald E. Ayer \\ Huntsman Cancer Institute, Department of Oncological Science, University of Utah, Salt Lake City, \\ Utah 84112-5550 \\ Correspondence: don.ayer@hci.utah.edu
}

Cell growth and division require the biosynthesis of macromolecule components and cofactors (e.g., nucleotides, lipids, amino acids, and nicotinamide adenine dinucleotide phosphate [NADPH]). Normally, macromolecular biosynthesis is under tight regulatory control, yet these anabolic pathways are often dysregulated in cancer. The resulting metabolic reprogramming of cancer cells is thought to support their high rates of growth and division. The mechanisms that underlie the metabolic changes in cancer are at least partially understood, providing a rationale for their targeting with known or novel therapeutics. This review is focused on how cells sense and respond transcriptionally to essential nutrients, including glucose and glutamine, and how MAX- and MLX-centered transcription networks contribute to metabolic homeostasis in normal and neoplastic cells.

\begin{abstract}
$M$ YC, also known as c-Myc, is a member of the basic helix-loop-helix leucine zipper (bHLHZip) family of transcription factors. MYC typically functions as a heterocomplex with the MAX bHLHZip protein to bind CANNTG sites that typically lie within a few kilobases of the transcriptional start site of a regulated gene. MYC, as discussed elsewhere in this volume, has pleiotropic functions in cell physiology that stem from its regulation of $10 \%-15 \%$ of the RNA polymerase II-dependent transcriptome, regulation of polymerase I and III transcription and its positive regulation of DNA replication (Eilers and Eisenman 2008). With this broad spectrum of functional targets, it is not surprising that MYC dysregulation is
\end{abstract}

implicated in up to $70 \%$ of human malignancy (Dang 2012b). No single, or even small collection, of MYC target(s) seems to be sufficient for its function as an oncogene. This finding is underscored by two recent reports suggesting that MYC functions as an "amplifier" of gene expression (Lin et al. 2012; Nie et al. 2012). The recent discovery that bromodomain inhibitors JQ1 and IBET-151 result in potent MYC downregulation raises the possibility that the therapeutic targeting of MYC-dependent cancers may soon be possible (Filippakopoulos et al. 2010; Delmore et al. 2011; Mertz et al. 2011).

One class of MYC targets of particular interest regulate cell metabolism, specifically glycolysis and glutaminolysis (Dang et al. 2009;

Editors: Chi V. Dang and Robert N. Eisenman

Additional Perspectives on MYC and the Pathway to Cancer available at www.perspectivesinmedicine.org

Copyright (C) 2013 Cold Spring Harbor Laboratory Press; all rights reserved; doi: 10.1101/cshperspect.a014258

Cite this article as Cold Spring Harb Perspect Med 2013;3:a014258 
J.M. O'Shea and D.E. Ayer

Dang 2012a). A seminal paper from the Dang laboratory in 1997 showed that lactate dehydrogenase is a MYC target and is required for MYCdependent glycolysis (Shim et al. 1997). It is now known that MYC regulates the expression of virtually every gene encoding an enzyme of the glycolytic pathway. More recent papers show that MYC directly or indirectly, through the regulation of microRNAs, controls the expression of genes required for glutamine uptake or glutamine utilization (Dang 2012b). Glycolysis and glutaminolysis fuel much of macromolecular biosynthesis, establishing MYC as an important regulator of the anabolic processes required for cell growth. Further, targeting MYC-dependent changes in cancer metabolism may be a new and fruitful avenue for the development of new therapeutics. A number of excellent recent review articles highlight dysregulated metabolic pathways in cancer more broadly (Deberardinis et al. 2008; Vander Heiden et al. 2009; Dang 2012a; Ward and Thompson 2012).

Our group identified and has studied the transcription factor MLX interacting protein (MLXIP), also known as MondoA, for several years. MondoA is also a bHLHZip factor and like MYC, MondoA has important functions in cell metabolism. Rather than controlling nutrient utilization directly like MYC, MondoA appears to function primarily in how cells sense, respond to, and coordinate the utilization of glucose and glutamine (Sans et al. 2006; Stoltzman et al. 2008, 2011; Kaadige et al. 2009; Peterson et al. 2010; Peterson and Ayer 2011; Havula and Hietakangas 2012). At present, our understanding of the functional interactions between MYC and MondoA is limited. However, current data suggest that MYC dysregulation and inactivation of MondoA are important drivers of metabolic reprogramming in cancer.

\section{MLXIP/MondoA BASICS}

As illustrated in Figure 1, MondoA interacts with another bHLHZip protein called MLX (MAX-like-protein X) and MondoA:MLX heterodimers, following regulated nuclear entry, are capable of binding promoters of target genes containing carbohydrate response ele- ment (ChoRE) binding sequences, two E-boxes separated by five nucleotides, and regulating their expression (Kaadige et al. 2010; Sloan and Ayer 2010; Peterson and Ayer 2011). At 919 amino acids, MLXIP is among the largest bHLHZip proteins. MLX, as the name implies, is more MAX-like in size, with three isoforms, $\alpha$, $\beta$, and $\gamma$, encoded by 214,244 , and 298 amino acids open reading frames, respectively. Compared with MAX, MLX apparently has a more restricted set of protein partnerships. In addition to MondoA, MLX it is known to interact with the MondoA paralog MLX interacting protein-like (MLXIPL), also known as MondoB or carbohydrate response element binding protein (ChREBP), as well as MXD1, MXD4, and MNT (McFerrin and Atchley 2011). The shared binding of MAX and MLX for MXD1, MXD4, and MNT provides a physical connection and the opportunity for functional cross talk between MAX-centered and MLX-centered transcriptional networks (Fig. 1). It is worth noting that the last hydrophobic residue of the leucine zipper of MLX, which mediates heterotypic interactions between bHLHZip proteins, is a tyrosine. This terminal tyrosine is only found in the leucine zipper of MLX family members and is universally conserved across metazoans (McFerrin and Atchley 2011). It is possible that MLX has expanded alternative protein partnerships under signaling conditions that result in phosphorylation of this tyrosine residue.

In addition to the bHLHZip domain, MondoA has a number of other conserved regions of functional significance. MondoA and MLX interact through their bHLHZip and dimerization and cytoplasmic localization domain (DCD). Like MAX, MLX appears to lack a transactivation domain (TAD); however, MondoA has a potent TAD localized in the middle third of its open reading frame (Billin et al. 2000; Billin and Ayer 2006). The amino terminus of the Mondo family (MondoA and ChREBP) has five regions that we have called Mondo conserved regions (MCR). The MCRs are highly conserved across metazoans and are easily identifiable in lower eukaryotes, suggesting an important and ancestral function (Fig. 1) (Kaadige et al. 2010; McFerrin and Atchley 
MAX- and MLX-Centered Transcription Networks

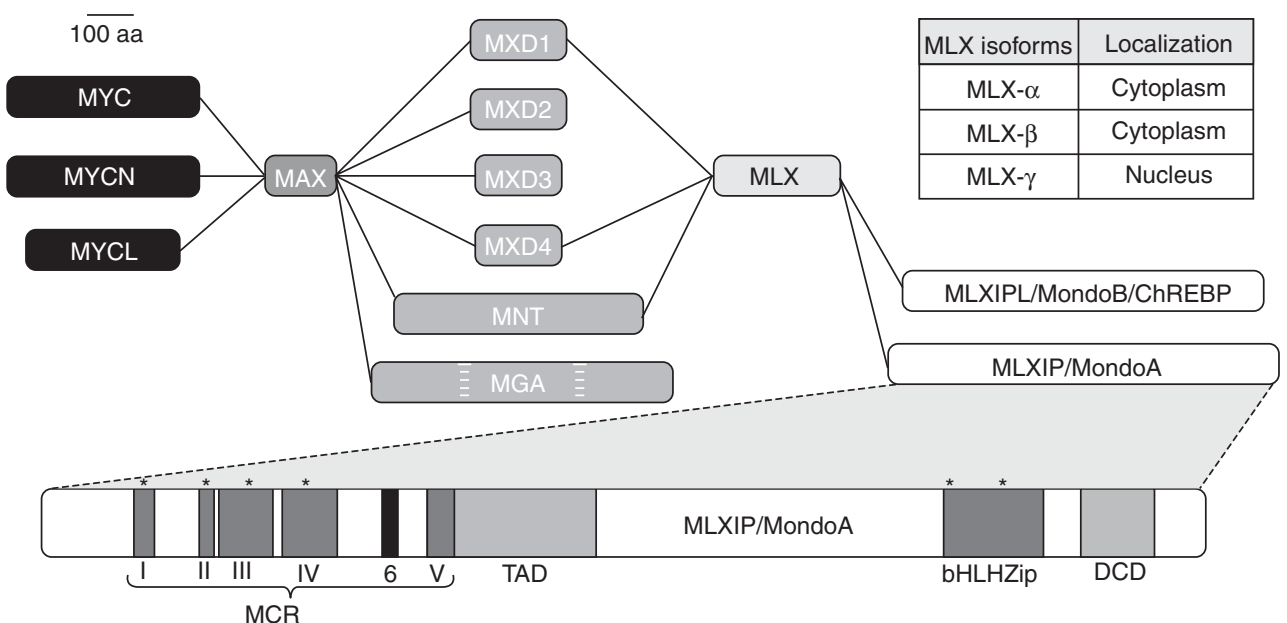

\begin{tabular}{|c|c|c|}
\hline${ }^{*}$ & Mutations & Defect \\
\hline MCRI & H78A/H81A/H88A & Cytoplasmic localization and impaired transcriptional activity \\
\hline MCRII & M133A & Nuclear localization and moderately impaired transcriptional activity \\
\hline MCRIII & I166A/W167A/R168A & Cytoplasmic localization and impaired transcriptional activity \\
\hline MCRIV & Y210D/Y211D/K212D & Nuclear localization and enhanced transcriptional activity \\
\hline MCRV & Deletion & Nuclear localization and enhanced transcriptional activity \\
\hline bHLHZip & H724P & DNA-binding mutant with impaired nuclear accumulation and ablated transcriptional activity \\
\hline bHLHZip & I766P & MLX-binding mutant with ablated nuclear localization and transcriptional activity \\
\hline
\end{tabular}

Figure 1. MAX- and MLX-centered transcriptional network. MAX binding proteins form one node of this transcriptional network, whereas MLX binding proteins form the second node. Competition for binding of MXD1, MXD4, and MNT provide one potential mechanism for interaction between the two nodes of the transcriptional network. MLX isoforms display distinct subcellular localization suggesting that complex switching may occur to facilitate nuclear accumulation and transcriptional regulation. Domain structure of MLXIP including the Mondo conserved regions (MCR), the transcriptional activation domain (TAD), the basic helixloop-helix leucine zipper (bHLHZip), and the dimerization and cytoplasmic localization domain (DCD). Mutations introduced into individual MCR and bHLHZip domains lead to effects on subcellular localization and transcriptional activity. 100 aa, 100 amino acids.

2011). As described below, the nuclear localization and transcriptional activity of MondoA: MLX complexes is controlled by glucose-6phosphate (G6P) and we have suggested that G6P interacts directly with the MCRs to control the nuclear activity of MondoA:MLX complexes by an allosteric mechanism (Stoltzman et al. 2008; Peterson et al. 2010). Consistent with this, a recent in-depth phylogenetic study of MondoA's amino terminus proposed the existence of MCR6. This additional domain was suggested based on its similarity to G6P binding domains in glucose phosphate isomerase (GPI) and glutamine-fructose-6-phosphate transaminase 1 (GFPT1) (McFerrin and Atchley 2012).
MondoA and ChREBP are close paralogs sharing extensive homology in their MCR (52\% identical), bHLHZip (61\% identical), and DCD (70\% identical) domains (Billin and Ayer 2006; McFerrin and Atchley 2011). Like MondoA, ChREBP also functions as a glucose sensor and interacts with MLX (Uyeda and Repa 2006; Postic et al. 2007; Havula and Hietakangas 2012). Here we limit our discussion to the functions of the MCRs of MondoA, although the analogous domains in ChREBP seem to function similarly. Initially, MondoA and ChREBP were found to be most highly expressed in skeletal muscle and liver, respectively (Billin et al. 2000; Uyeda and Repa 2006; Postic 
et al. 2007). Given the important role played by these tissues in glucose homeostasis, this expression pattern makes sense from a physiological perspective. However, both MondoA and ChREBP are broadly expressed in most tissues (www.biogps.org) and likely have uncharacterized functions outside of controlling glucose homeostasis.

One unique feature of MondoA:MLX complexes is that they are not constitutively nuclear, like other members of the MYC, MAX, and MXD families. Rather they localize to the outer membrane of the mitochondria (OMM) and shuttle between the OMM and the nucleus (Sans et al. 2006), providing an initial subcellular localization regulatory step. Given the multifaceted role played by mitochondria in bioenergetics, we initially postulated that MondoA:MLX complexes sense some aspect of intracellular energy status and communicate that information to the nucleus to trigger an adaptive transcriptional response. We now know that MondoA:MLX complexes sense glucose and other hexoses and play a predominant role in regulating glucose-induced transcription in murine embryonic fibroblasts (MEFs), HA1ER cells, and a breast epithelial cell line transformed with SV40 large T antigen and activated H-Ras (Stoltzman et al. 2008). ChREBP, which is also held latently in the cytoplasm but not at the OMM, plays a similarly predominant role in controlling glucose-induced transcription in rat hepatocytes (Ma et al. 2006). For both MondoA:MLX and ChREBP:MLX complexes, glucose drives nuclear accumulation and promoter binding of the heterodimers.

How glucose controls the nuclear accumulation and transcriptional activity of MondoA:MLX and ChREBP:MLX complexes is potentially quite complicated and no unifying model has yet emerged. Early models of ChREBP regulation implicated a number of glucose-dependent phosphorylation and dephosphorylation events in controlling ChREBP nuclear activity (Uyeda and Repa 2006; Postic et al. 2007). These early reports are controversial and have been revisited several times (Postic et al. 2007). More recent reports suggest allosteric models in which glucose-derived metabolites such as glucose 6-phosphate, xylulose 5-phosphate, and fructose 2,6-bisphosphate control the nuclear activity of MondoA and ChREBP (Li et al. 2010; Arden et al. 2012; Dentin et al. 2012; Petrie et al. 2013). Interestingly, target gene selection by MondoA and ChREBP seems to be dictated by specific metabolites. For instance, glucose and the nonglucose hexoses allose and 3-O-methylglucose, induce MondoA binding to the thioredoxin interacting protein (TXNIP) promoter, whereas only glucose induces MondoA binding to the protein targeting to glycogen promoter (Stoltzman et al. 2011; Petrie et al. 2013).

The phosphoacceptor sites identified in ChREBP are not conserved in MondoA, suggesting that MondoA:MLX complexes do not use the same glucose-dependent phosphoregulation. Several lines of evidence support the model that MondoA:MLX complexes sense glucose 6-phosphate (Stoltzman et al. 2008). For example, nuclear accumulation of MondoA:MLX complexes require the enzymatic activity of hexokinases, which phosphorylate glucose to glucose 6-phosphate (G6P) (Stoltzman et al. 2008). Both glucose and 2DG induce the nuclear translocation of MondoA:MLX complexes, but 2DG is more effective than glucose. 2DG is phosphorylated by hexokinases but is not further metabolized by the glycolytic pathway. Thus, phosphorylated 2DG builds up to a significantly higher level than G6P and we proposed that this accounts for the higher activity of 2DG in driving MondoA:MLX to the nucleus. Supporting this hypothesis, cells that lack phosphoglucose isomerase cannot isomerize G6P to fructose 6-phosphate and accumulate G6P. In these cells glucose and 2DG are equally effective at driving nuclear accumulation of MondoA:MLX complexes (Stoltzman et al. 2011). Together these experiments support an important role for G6P. However, metabolites downstream from G6P also regulate MondoA:MLX transcriptional activity. For example, glucosamine 6-phosphate, a metabolite of the hexosamine biosynthetic pathway, can also drive nuclear accumulation of MondoA:MLX complexes (Stoltzman et al. 2011). Determining which metabolites regulate MondoA:MLX complexes directly will almost 
certainly require deciphering the mechanistic details in vitro.

Regardless of the exact mechanism(s) by which glucose regulates MondoA:MLX nuclear accumulation, the target is almost certainly the MCRs. For example, deletion of the MCRs renders MondoA:MLX complexes constitutively nuclear and transcriptionally active in the complete absence of glucose. Introducing point mutations in highly conserved residues in individual MCRs fails to phenocopy the deletion of MCR I-V, suggesting that the MCRs function as a structural unit (Fig. 1) (Eilers et al. 2002; Peterson et al. 2010). Further supporting this hypothesis is the fact that the spacing between

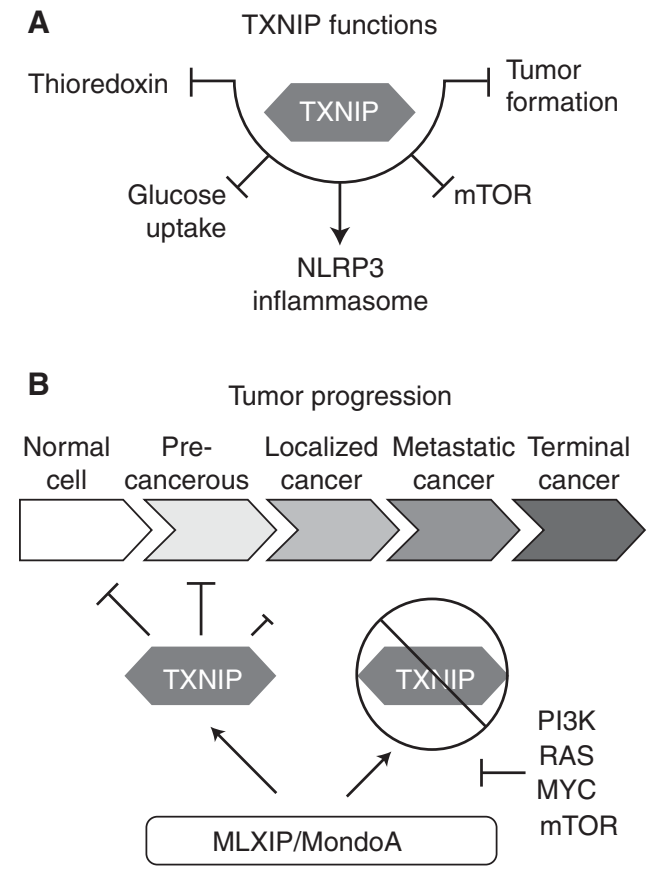

Figure 2. Cellular roles for TXNIP. (A) TXNIP functions in numerous contexts within the cell. Prominent roles include inhibition of the redox protein thioredoxin (TXN), restricting glucose uptake through multiple potential mechanisms, inhibition of mTOR signaling via REDD1 stabilization, and restricting tumor formation. (B) MLIXP-TXNIP signaling serves to restrict cell growth via a metabolic or stress checkpoint. Disruption of this regulatory circuit is one potential mechanism that cells use to transition to an unrestricted growth phenotype, commonly found in cancer cells.
MAX- and MLX-Centered Transcription Networks

MCRs II-IV is nearly invariant across species. The spacing between MCRI and MCRII and between MCRIV and MCRV is slightly more variable; however, the linear order and presumably the structure of the MCRs are conserved across species (McFerrin and Atchley 2012). Little is known about the function of the individual MCRs. MCRII contains a CRM1-dependent nuclear export signal and MCRIII binds 14-3-3 isoforms. Current data suggest that 14-3-3 binding to MCRIII occludes CRM1 binding to MCRII, resulting in nuclear localization of the MondoA:MLX heterocomplex (Eilers et al. 2002). However, MondoA mutants with mutations in MCRII are constitutively nuclear, yet fail to bind target gene promoters and activate gene expression in the absence of glucose. Thus, nuclear accumulation of MondoA:MLX complexes is not sufficient to activate gene expression (Peterson et al. 2010). Whether MCRI, MCRIV, or MCRV form additional protein partnerships is not known; however, it is possible that they participate in intramolecular interactions that stabilize the structure of the entire MCR domain.

\section{THE MondoA-TXNIP NEGATIVE- FEEDBACK LOOP}

The best-characterized glucose-induced direct transcriptional target of MondoA:MLX complexes is TXNIP. TXNIP as its name implies was identified as a binding partner and negative regulator of the small redox protein thioredoxin (TXN) (Chen et al. 2008a; Jin et al. 2011; Zhou et al. 2011; Patwari and Lee 2012). TXNIP has pleiotropic functions in the cell, most prominent among these being the regulation of reactive oxygen species by inhibiting TXN function, and blocking glucose uptake and aerobic glycolysis (Fig. 2A). Recently, TXNIP has been shown to suppress mammalian target of rapamycin (mTOR) activity via stabilization of REDD1 (Jin et al. 2011). TXNIP has also been implicated as a functional component of the NRLP3 inflammasome, required for the cleavage and production of functional IL-1 $\beta$ (Schroder et al. 2010). TXNIP is thought to be a tumor suppressor in a number of cancers and TXNIP 
knockout mice are prone to develop hepatocellular carcinoma (HCC) spontaneously (Sheth et al. 2006; Zhou et al. 2011). This may reflect TXNIP's proapoptotic activity, its stabilization of the cell-cycle inhibitor p27Kip1 (CDK1B), its destabilization of hypoxia inducible factor $1 \alpha$ (HIF-1 $\alpha$ ), or its negative regulation of glucose utilization (Jeon et al. 2005; Muoio 2007; Parikh et al. 2007; Shin et al. 2008; Stoltzman et al. 2008, 2011). TXNIP also appears to play prominent roles in organismal glucose homeostasis by regulating peripheral glucose uptake and glucose toxicity of pancreatic $\beta$ cells (Parikh et al. 2007; Chen et al. 2008a). A complete accounting of TXNIPs functions is not possible here, although several recent reviews are available (Kim et al. 2007; Muoio 2007; Zhou et al. 2011; Patwari and Lee 2012; Zhou and Chng 2012).

Multiple experiments illustrate that TXNIP is a direct and glucose-induced target of MondoA. First, TXNIP levels are reduced or not detectable in MondoA knockdown or knockout cells grown in glucose-containing medium. Similarly, glucose induction of TXNIP is reduced or eliminated in MondoA knockdown or knockout cells (Stoltzman et al. 2008, 2011; Kaadige et al. 2009; Chen et al. 2010a; Peterson et al. 2010). Thus, MondoA is required for TXNIP expression under basal glucose conditions and glucose induction. Second, MondoA:MLX complexes accumulate rapidly in the nucleus following glucose addition and this nuclear accumulation is not blocked by the protein synthesis inhibitor cycloheximide. Third, MondoA can be detected on the TXNIP promoter in a region that contains a ChoRE within 15 minutes of glucose addition (Stoltzman et al. 2008). Finally, the activity of a TXNIP luciferase reporter was virtually eliminated by mutating the ChoRE. Collectively, these experiments suggest that the nuclear accumulation of MondoA:MLX and its regulation of TXNIP is an immediate early response to changes in the flux of glucose into the glycolytic pathway.

Among TXNIP's many functions is a blockade of glucose uptake and aerobic glycolysis (Fig. 2A). Thus, the glucose-dependent induction of TXNIP by MondoA:MLX complexes constitutes a negative-feedback loop that restricts glucose uptake when glycolytic flux is high. A close paralog of TXNIP is arrestin domain-containing protein 4 (ARRDC4), whose expression is also glucose induced in a MondoA:MLX-dependent manner (Kaadige et al. 2009; Peterson et al. 2010). ARRDC4 can also restrict glucose uptake (Patwari et al. 2009), so TXNIP and ARRDC4 likely function in concert or redundantly downstream from MondoA:MLX complexes to restrict glucose availability (Sloan and Ayer 2010). TXNIP may restrict glucose by binding the glucose transporter GLUT1, and internalization of the transporter via clathrin-coated pits ( $\mathrm{Wu}$ et al. 2013). Several additional potential mechanisms for TXNIP restricting glucose uptake include destabilization of HIF1A, interactions with endosomal sorting complex required for transport (ESCRT) machinery, or control of PTEN activity (Hui et al. 2008; Shin et al. 2008; Rauch and Martin-Serrano 2011). What is clear is that TXNIP can block both insulin-independent and insulin-induced glucose uptake and that this function of TXNIP does not require its interaction with TXN (Patwari et al. 2009). The multiple mechanisms by which TXNIP may restrict glucose uptake suggest that its function may depend on cell context.

Considerable evidence supports a physiological role for the MondoA:MLX-TXNIP negative-feedback loop in restricting glucose uptake. For example, reduction of MLXIP or TXNIP triggers elevated glucose uptake and aerobic glycolysis. Following activation of naïve $\mathrm{T}$ cells, TXNIP protein and mRNA expression are restricted after 24 hours and this is concomitant with reprogramming to a highly glycolytic metabolic profile (Elgort et al. 2010). Furthermore, TXNIP induction is required for glucoseinduced pancreatic $\beta$-cell apoptosis (Chen et al. 2008a). Thus, loss of MondoA or TXNIP is sufficient to trigger metabolic reprogramming toward one of the most common phenotypic features of the transformed state. Further, expression of a dominant active form of MondoA can potently block glucose uptake and this reduction of glucose uptake is partially dependent on elevated TXNIP levels (Hui et al. 2008; 
Kaadige et al. 2009; Stoltzman et al. 2011). Thus, TXNIP is a required effector of MondoA-dependent reduction of glucose uptake, yet other MondoA targets must also be required. ARRDC4 is one obvious candidate. Finally, MondoA and TXNIP are required for the full elaboration of the hexose curb, the restriction of glucose uptake following exposure to different hexose sugars (Stoltzman et al. 2011). The MondoA-TXNIP regulatory circuit is extant in many cell types and is predicted to have growth-suppressive functions. However, MondoA appears to have growth-promoting functions in B-cell acute lymphocytic leukemia (B-ALL), suggesting that its regulation TXNIP may be restricted in some cell types (Wernicke et al. 2012).

\section{GLUTAMINE-DEPENDENT REPRESSION OF TXNIP}

In addition to glucose, the amino acid glutamine is also typically required for cell growth (Deberardinis et al. 2008). Much like glucose, glutamine can flux into a number of metabolic or biosynthetic pathways, yet glucose-stimulated induction of TXNIP can be repressed by glutamine. The presence of glutamine effects neither the glucose-induced nuclear accumulation of MondoA:MLX complexes nor their binding to the TXNIP promoter. In contrast, glutaminedependent repression of the TXNIP promoter can be completely reversed with a histone deacetylase (HDAC) inhibitor, suggesting that glutamine triggers the activation, or the recruitment of a HDAC complex to the TXNIP promoter (Kaadige et al. 2009). Given that MondoA:MLX complexes are such potent activators of TXNIP gene expression, we have proposed that they are required for HDAC targeting, yet it is possible that other transcription factors recruit a HDAC-containing corepressor complex to the TXNIP promoter in the presence of glutamine. In this case, the glutaminetargeted repression would be dominant over the potent MondoA-dependent activation of TXNIP.

As glutamine has several intracellular fates (DeBerardinis and Cheng 2010; Shanware et al. 2011), there are several potential mechanisms
MAX- and MLX-Centered Transcription Networks

by which it may drive TXNIP gene repression. Although it is difficult to rule out minor contributions from other pathways, several experiments point to a predominant role for $\alpha$-ketoglutarate $(\alpha-K G) . \alpha-K G$ is generated from glutamine through several distinct pathways. Once glutamine enters the cell it is hydrolyzed to glutamate and an ammonium ion in a reaction catalyzed by glutaminase. Glutamate can be converted to $\alpha$-KG by one of three mechanisms: (1) glutamate can be converted to $\alpha-\mathrm{KG}$ and an ammonium ion in a reaction catalyzed by glutamate dehydrogenase; (2) the amino group of glutamate can be transferred to the keto group of pyruvate to generate $\alpha-\mathrm{KG}$ and alanine in a reaction catalyzed by alanine transaminase (GPT); and (3) the amino group of glutamate can be transferred to the keto group of oxaloacetate to generate $\alpha-K G$ and aspartate in a reaction catalyzed by aspartate transaminase (GOT1). Aminooxyacetate (AOA) inhibits GPT and GOT1, blocking the formation of $\alpha$-KG. AOA effectively inhibits glutaminedependent repression of TXNIP suggesting a role for $\alpha-K G$ as an important effector in this process. Importantly, cell permeable analogs of $\alpha-K G$, which restore intracellular $\alpha-K G$ levels in glutamine-depleted cells, completely phenocopy glutamine-dependent repression of TXNIP and bypass the AOA blockade to reduce TXNIP expression. Together, these findings implicate $\alpha-K G$ as a key mediator of glutaminedependent repression of TXNIP (Kaadige et al. 2009). In each of these experimental treatments, high TXNIP expression tracked with lower glucose uptake. Thus, a final implication of finding that $\alpha-K G$ can repress TXNIP and stimulate glucose uptake is that TCA function may actually lie upstream and modulate glycolysis under some circumstances.

There are several mechanisms by which $\alpha$ KG may drive repression of TXNIP gene expression. First, as $\alpha-K G$ can replenish the TCA cycle, it is possible that TXNIP promoter activity is directly linked to this central metabolic process (Kaadige et al. 2009). In this regard, the shuttling of MondoA:MLX between the OMM and the nucleus places it in the perfect cellular context to be regulated by mitochondrial cues (Sans 
et al. 2006). Determining the site of action for $\alpha$-KG-dependent repression of TXNIP and whether $\alpha$-KG or an $\alpha$-KG-derived metabolite is sufficient for TXNIP repression will help clarify this mechanism. A second possibility stems from $\alpha$-KGs role as a cofactor for a number of dioxygenases that have established roles in controlling gene expression or emerging roles in controlling epigenetics (DeBerardinis and Thompson 2012; Yun et al. 2012). This may potentially lead to TXNIP repression through a more indirect mechanism. For example, $\alpha-K G$ is required for the prolyl hydroxylases PHD1 and PHD2, to modify and target HIF1A for degradation. In addition, $\alpha-K G$ is required for the activity of the TET family of DNA demethylases and for the Jumonji family of histone demethylases. Activation of TET demethylases typically results in gene activation, seemingly ruling out this mechanism. In contrast, Jumonji demethylases can contribute to gene activation or repression depending on the histone substrate. Data available from the Santa Cruz genome browser (www.genome.ucsc.edu) shows that the promoter of the TXNIP gene is enriched with histone $\mathrm{H} 3$ that is trimethylated at lysine 4 (H3K4me3), an activation mark. This raises the possibility that a histone demethylase from the JARID family, which targets (H3K4me3), could contribute to glutamine-dependent repression of TXNIP. It is also conceivable that an $\alpha$-KG-dependent dioxygenase modifies MondoA to control its transcriptional activity.

\section{DOES THE MondoA-TXNIP CIRCUIT CONTRIBUTE TO TUMOR SUPPRESSION?}

TXNIP has pleiotropic effects in cell physiology and most of these are growth suppressive, suggesting that TXNIP may be a bona fide tumor suppressor. As recently reviewed, TXNIP has been implicated as a tumor suppressor in a number of different cancers including hepatocellular carcinoma, breast cancer, bladder cancer, gastric cancer, and leukemia (Zhou et al. 2011). TXNIP null animals are prone to hepatocellular carcinoma late in life (Sheth et al. 2006), but there are no published studies examining whether TXNIP loss can accelerate tumor- igenesis driven by other oncogenes. Whether a single function of TXNIP or multiple functions mediate its growth-suppressive function is unknown.

The putative role of TXNIP as a tumor suppressor has been best studied in breast cancer. One study of 788 patients found high TXNIP mRNA expression portended a better prognosis (Cadenas et al. 2010). In a second study, the Chi laboratory identified a protective gene signature that was induced by lactic acidosis (LA), which is a common feature of the tumor microenvironment. TXNIP and ARRDC4 were induced by LA exposure and were important components of this protective LA-dependent gene signature (Chen et al. 2008b). In collaboration with the Chi group, we showed that the LAinduced increase in TXNIP was entirely dependent on MondoA and glucose. Further, we used chromatin immunoprecipitation (ChIP) to show that MondoA occupies the TXNIP promoter more robustly under LA growth conditions (Chen et al. 2010a). This finding suggests that LA controls either the amount of MondoA in the nucleus or the DNA-binding activity of MondoA:MLX complexes, rather than controlling the transcriptional activity of MondoA: MLX complexes.

Because TXNIP expression is strictly dependent on MondoA, we have suggested that MondoA may also have a tumor suppressor function in breast cancer. MondoA levels are not generally suppressed in breast cancer, yet given that nuclear and transcriptional activity of MondoA is under complex regulatory control, it is possible that negative regulation of MondoA nuclear activity is more relevant than absolute levels of MondoA protein to a putative growth-suppressive activity. MondoA mRNA levels are suppressed in several types of lymphoma, including Burkitt's lymphoma, which typically has dysregulated MYC expression, superficial bladder cancer, infiltrating bladder urothelial carcinoma, colorectal carcinoma, rectal and colon mucinous adenocarcinoma, prostatic intraepithelial neoplasia, and several types of sarcoma (Fig. 3) (Basso et al. 2005; Detwiller et al. 2005; Sanchez-Carbayo et al. 2006; Tomlins et al. 2007). TXNIP mRNA levels are also generally lower in 


\begin{tabular}{|c|c|c|c|}
\hline & Cancer & $\begin{array}{l}\text { rold } \\
\text { change }\end{array}$ & $P$ value \\
\hline & $\begin{array}{l}\text { Superficial bladder cancer } \\
\text { (Sanchez-Carbayo et al. 2006) }\end{array}$ & -4.53 & $6.65 \mathrm{E}-12$ \\
\hline & $\begin{array}{l}\text { Infiltrating bladder urothelial ca } \\
\text { (Sanchez-Carbayo et al. 2006) }\end{array}$ & $\begin{array}{l}\text { arcinoma } \\
-2.37\end{array}$ & $3.70 \mathrm{E}-10$ \\
\hline & Prostatic intraepithelial neoplas & & \\
\hline & (Tomlins et al. 2007) & -2.70 & $1.53 \mathrm{E}-6$ \\
\hline & $\begin{array}{l}\text { Burkitt's lymphoma } \\
\text { (Basso et al. 2005) }\end{array}$ & -2.50 & $1.45 \mathrm{E}-5$ \\
\hline & $\begin{array}{l}\text { Rectal mucinous carcinoma } \\
\text { (TCGA) }\end{array}$ & -2.22 & $4.43 E-5$ \\
\hline & $\begin{array}{l}\text { Colon mucinous carcinoma } \\
\text { (TCGA) }\end{array}$ & -2.01 & $1.10 \mathrm{E}-8$ \\
\hline & B-cell acute lymphoblastic leuk & kemia & \\
\hline & (Haferlach et al. 2010) & 3.46 & $1.32 \mathrm{E}-58$ \\
\hline & $\begin{array}{l}\text { B-cell childhood acute lymphob } \\
\text { (Haferlach et al. 2010) }\end{array}$ & $\begin{array}{c}\text { blastic le } \\
3.43\end{array}$ & $\begin{array}{l}\text { eukemia } \\
1.29 \mathrm{E}-69\end{array}$ \\
\hline$\stackrel{\stackrel{P}{\Sigma}}{\Sigma}$ & $\begin{array}{l}\text { Prostate adenocarcinoma } \\
\text { (Wallace et al. 2008) }\end{array}$ & 3.63 & 7.17E-5 \\
\hline & $\begin{array}{l}\text { Clear cell renal cell carcinoma } \\
\text { (Jones et al. 2005) }\end{array}$ & 3.08 & 4.86E-15 \\
\hline & $\begin{array}{l}\text { Invasive breast carcinoma } \\
\text { (Finak et al. 2008) }\end{array}$ & -7.05 & 4.29E-19 \\
\hline & $\begin{array}{l}\text { Colon adenocarcinoma } \\
\text { (TCGA) }\end{array}$ & -2.07 & $6.02 \mathrm{E}-15$ \\
\hline & $\begin{array}{l}\text { Colon mucinous adenocarcinor } \\
\text { (TCGA) }\end{array}$ & -2.00 & $4.16 \mathrm{E}-13$ \\
\hline$\stackrel{\times}{\stackrel{x}{\Sigma}}$ & $\begin{array}{l}\text { Rectal adenocarcinoma } \\
\text { (TCGA) }\end{array}$ & -2.05 & $9.06 \mathrm{E}-15$ \\
\hline & $\begin{array}{l}\text { Rectal mucinous adenocarcino } \\
\text { (TCGA) }\end{array}$ & $\begin{array}{l}\text { oma } \\
-2.77\end{array}$ & 7.43E-5 \\
\hline & $\begin{array}{l}\text { Cecum adenocarcinoma } \\
\text { (TCGA) }\end{array}$ & -2.34 & $2.30 \mathrm{E}-13$ \\
\hline & $\begin{array}{l}\text { Acute myeloid leukemia } \\
\text { (Stegmaier et al. 2004) }\end{array}$ & -3.48 & 4.09E-5 \\
\hline & $\begin{array}{l}\text { Benign melanocytic skin nevus } \\
\text { (Talantov et al. 2005) }\end{array}$ & 5.94 & $8.68 \mathrm{E}-5$ \\
\hline & $\begin{array}{l}\text { Diffuse astrocytoma } \\
\text { (Sun et al. 2006) }\end{array}$ & 2.61 & $1.55 \mathrm{E}-7$ \\
\hline$\underset{\sum}{\stackrel{L}{x}} \stackrel{2}{\longrightarrow}$ & $\begin{array}{l}\text { Anaplastic astrocytoma } \\
\text { (Sun et al. 2006) }\end{array}$ & 3.94 & 3.07E-8 \\
\hline & $\begin{array}{l}\text { Oligodendroglioma } \\
\text { (Sun et al. 2006) }\end{array}$ & 3.84 & $1.59 \mathrm{E}-15$ \\
\hline & $\begin{array}{l}\text { Brain glioblastoma } \\
\text { (Sun et al. 2006) }\end{array}$ & 2.63 & $1.38 \mathrm{E}-11$ \\
\hline
\end{tabular}

\begin{tabular}{|c|c|c|c|}
\hline & Cancer & change & $P$ value \\
\hline & $\begin{array}{l}\text { Hepatocellular carcinoma } \\
\text { (Roessler et al. 2010) }\end{array}$ & -2.05 & $1.21 \mathrm{E}-23$ \\
\hline & $\begin{array}{l}\text { Ovarian serous cystadenoc } \\
\text { (TCGA) }\end{array}$ & $\begin{array}{l}\text { arcinoma } \\
-2.13\end{array}$ & $3.87 \mathrm{E}-6$ \\
\hline & $\begin{array}{l}\text { Chronic lymphocytic leuker } \\
\text { (Haslinger et al. 2004) }\end{array}$ & $\begin{array}{l}\text { nia } \\
-2.28\end{array}$ & $1.87 \mathrm{E}-6$ \\
\hline & $\begin{array}{l}\text { Thyroid gland oncocytic ad } \\
\text { (Giordano et al. 2006) }\end{array}$ & $\begin{array}{l}\text { enoma } \\
-2.50\end{array}$ & $4.12 \mathrm{E}-5$ \\
\hline & $\begin{array}{l}\text { Ovarian carcinoma } \\
\text { (Bonome et al. 2008) }\end{array}$ & -3.58 & $8.80 \mathrm{E}-7$ \\
\hline & $\begin{array}{l}\text { Cutaneous melanoma } \\
\text { (Talantov et al. 2005) }\end{array}$ & -3.01 & $2.76 \mathrm{E}-5$ \\
\hline & $\begin{array}{l}\text { Tongue squamous cell carc } \\
\text { (Talbot et al. 2005) }\end{array}$ & $\begin{array}{l}\text { inoma } \\
-2.86\end{array}$ & $8.82 \mathrm{E}-8$ \\
\hline & $\begin{array}{l}\text { Colon adenocarcinoma } \\
\text { (TCGA) }\end{array}$ & -2.85 & $6.03 E-20$ \\
\hline & $\begin{array}{l}\text { Colon mucinous adenocarc } \\
\text { (TCGA) }\end{array}$ & $\begin{array}{l}\text { inoma } \\
-3.36\end{array}$ & $1.08 \mathrm{E}-13$ \\
\hline & $\begin{array}{l}\text { Rectal adenocarcinoma } \\
\text { (TCGA) }\end{array}$ & -4.01 & $1.99 \mathrm{E}-19$ \\
\hline & $\begin{array}{l}\text { Rectal mucinous adenocar } \\
\text { (TCGA) }\end{array}$ & $\begin{array}{r}\text { cinoma } \\
-3.85\end{array}$ & 8.03E-5 \\
\hline & $\begin{array}{l}\text { Cecum adenocarcinoma } \\
\text { (TCGA) }\end{array}$ & -4.07 & $1.48 \mathrm{E}-14$ \\
\hline 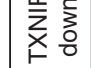 & $\begin{array}{l}\text { Squamous cell lung carcinc } \\
\text { (Garber et al. 2001) }\end{array}$ & -4.88 & $2.14 \mathrm{E}-6$ \\
\hline & $\begin{array}{l}\text { Lung carcinoid tumor } \\
\text { (Bhattacharjee et al. 2001) }\end{array}$ & -6.62 & $1.53 \mathrm{E}-6$ \\
\hline & $\begin{array}{l}\text { Dedifferentiated liposarcom } \\
\text { (Barretina et al. 2010) }\end{array}$ & -2.55 & $2.94 \mathrm{E}-12$ \\
\hline & $\begin{array}{l}\text { Pleomorphic liposarcoma } \\
\text { (Barretina et al. 2010) }\end{array}$ & -2.90 & $3.07 \mathrm{E}-8$ \\
\hline & $\begin{array}{l}\text { Myxoid/round cell liposarco } \\
\text { (Barretina et al. 2010) }\end{array}$ & $\begin{array}{l}\mathrm{ma} \\
-3.57\end{array}$ & $3.9 \mathrm{E}-11$ \\
\hline & $\begin{array}{l}\text { Leiomyosarcoma } \\
\text { (Barretina et al. 2010) }\end{array}$ & -4.26 & 2.77E-12 \\
\hline & $\begin{array}{l}\text { Myxofibrosarcoma } \\
\text { (Barretina et al. 2010) }\end{array}$ & -5.17 & $2.26 \mathrm{E}-14$ \\
\hline & $\begin{array}{l}\text { Mixed lobular and ductal br } \\
\text { (TCGA) } \\
\text { Invasive lobular breast carc } \\
\text { (TCGA) }\end{array}$ & $\begin{array}{l}\text { east carc } \\
-2.70 \\
\text { inoma } \\
-2.87\end{array}$ & $\begin{array}{l}\text { inoma } \\
8.15 E-5\end{array}$ \\
\hline & $\begin{array}{l}\text { Invasive ductal and lobular } \\
\text { (TCGA) }\end{array}$ & $\begin{array}{l}\text { breast ca } \\
-3.13\end{array}$ & $\begin{array}{l}\text { rcinoma } \\
9.32 \mathrm{E}-14\end{array}$ \\
\hline & $\begin{array}{l}\text { Invasive breast carcinoma } \\
\text { (TCGA) }\end{array}$ & -3.65 & $6.17 \mathrm{E}-24$ \\
\hline & $\begin{array}{l}\text { Invasive ductal breast carci } \\
\text { (TCGA) }\end{array}$ & $\begin{array}{l}\text { noma } \\
-4.94\end{array}$ & 5.01E-39 \\
\hline & $\begin{array}{l}\text { Mucinous breast carcinome } \\
\text { (TCGA) }\end{array}$ & -6.05 & $2.63 \mathrm{E}-18$ \\
\hline
\end{tabular}

Figure 3. MLXIP/MLX/TXNIP expression in tumor data sets. Oncomine (www.oncomine.org) was used to examine changes in MLXIP, MLX, and TXNIP in different cancers. Fold up- or down-regulation is listed along with the $P$ value. Following each cancer type is the first investigator of the primary research study. Names listed in parentheses are the individual references. TCGA, The Cancer Genome Atlas. 
many of these same tumors suggesting that the MondoA-TXNIP regulatory circuit may be impaired in these cancer types potentially contributing to their transformed phenotype (Fig. 3) (Bhattacharjee et al. 2001; Garber et al. 2001; Haslinger et al. 2004; Talantov et al. 2005; Talbot et al. 2005; Giordano et al. 2006; Bonome et al. 2008; Barretina et al. 2010; Roessler et al. 2010). However, TXNIP is overexpressed in some cancers suggesting that the role of TXNIP in tumor progression is likely to be context dependent (Talantov et al. 2005; Sun et al. 2006). Perhaps related to this finding, the locus that encompasses the TXNIP gene is amplified in some cancer types (www.cbioportal.org); however, further analysis is required to determine how changes in TXNIP gene copy number relate to TXNIP mRNA and protein expression. Finally, dimerization with MLX is essential for MondoA to access the nucleus and activate gene expression (Peterson et al. 2010). It is intriguing that MLX mRNA levels are reduced in breast and colon cancer and acute myeloid leukemia (Fig. 3) (Stegmaier et al. 2004; Finak et al. 2008), suggesting another route to inactivation of the transcriptional activity of MondoA:MLX complexes and loss of the MondoA-TXNIP circuit.

Most of the current literature supports a growth/tumor suppressive role for the MondoA-TXNIP circuit; however, MondoA is up-regulated in B-ALL, prostate adenocarcinoma, and clear cell renal carcinoma (Fig. 3) (Jones et al. 2005; Wallace et al. 2008; Haferlach et al. 2010). Surprisingly, MondoA promoted glucose uptake in B-ALL cell lines rather than suppressed glucose uptake as shown for the MondoA-TXNIP circuit in other cell types. Further, in a B-ALL cell line, MondoA regulated a "stemness" gene signature and MondoA expression correlated with a more immature and less differentiated cell fate (Wernicke et al. 2012). Interestingly, the gene expression signature generated following MondoA knockdown showed significant overlap with a gene signature that portended a good prognosis for B-ALL patients treated with glucocorticoids (Rhein et al. 2007). This finding contrasts with other reports indicating that TXNIP contributes to glucocorticoid-driven apoptosis in a number of T-cell leu- kemia cell lines (Wang et al. 2006; Chen et al. 2010b). It may be that in B-ALL, MondoA cannot regulate TXNIP and this tumor/growthsuppressive axis is not intact. These seemingly contradictory findings underscore the necessity of understanding the full spectrum of MondoA targets in different cell lineages in both physiological and pathophysiological states.

\section{METABOLIC REPROGRAMMING IN G - $^{-}$ INACTIVATION OF THE MondoA-TXNIP CIRCUIT}

Once stimulated, quiescent cells must dramatically reprogram their metabolism to support their biosynthetic requirements (Wang and Green 2012) to transit the $G_{1}$ phase of the cell cycle and enter S phase. However, cells become independent of both growth factors and nutrients after mid- $G_{1}$ (Pardee 1974), indicating that they accumulate sufficient biomolecular precursors to support cell division during $\mathrm{G}_{1}$. Serum starved, quiescent BJ-TERT cells, an immortal but diploid fibroblast cell line derived from human foreskin, acutely down-regulate the MondoA-TXNIP circuit following serum stimulation, paralleling a rapid up-regulation of glucose uptake and glycolysis, indicative of metabolic reprogramming (Elgort et al. 2010). MondoA-dependent transcriptional activation of TXNIP is blocked by PI3K signaling, whereas translation of preexisting TXNIP mRNA is blocked by Ras signaling. Importantly, constitutive expression of MondoA or TXNIP slows progression into $S$ phase indicating that TXNIP down-regulation is necessary for cells to efficiently transit the $G_{1}$ phase and is not just correlated with this transition. This indicates that abrogation of the MondoA-TXNIP circuit is a required component of the metabolic reprogramming toward aerobic glycolysis required to transition from $G_{0}$ to $S$ phase, and implies a potential role for MondoA in activation of quiescent stem cell populations.

It is noteworthy that the biosynthetic metabolism of cells in $G_{1}$ mirrors that of cancer cells. In normal human fibroblasts, activation of PI3K and Ras contribute to the down-regulation of the MondoA-TXNIP circuit. Given the 
preponderance of PI3K and Ras activation in cancer and their established function in driving aerobic glycolysis (Shaw and Cantley 2006), we propose that their suppression of the MondoATXNIP circuit may be a general feature of the metabolic phenotype observed in many cancers (Fig. 2B). From a cancer perspective, we suggest that the MondoA-TXNIP regulatory circuit constitutes a metabolic or stress checkpoint that restricts cell growth. In nontransformed cells, MondoA-dependent up-regulation of TXNIP serves to restrict cell growth until the stress can be resolved. In contrast, in cells with constitutive activation of the PI3K pathway and/or Ras, TXNIP levels remain low allowing these cells to bypass this metabolic/ stress checkpoint (Fig. 2B).

\section{INTERACTIONS BETWEEN NUTRIENT UTILIZATION AND NUTRIENT AVAILABILITY}

MYC has pleiotropic functions in controlling glycolysis, yet its broad reach in controlling cell metabolism extends to mitochondrial activity and glutaminolysis. MYC controls glutaminolysis, in part by up-regulating glutamine transporters and glutaminase, suggesting that MYC overexpressing cells can preferentially use glutamine as a carbon source to fuel biosynthetic reactions (Wise et al. 2008; Gao et al. 2009). Supporting this hypothesis, MYC overexpression renders IMR90 diploid fibroblasts sensitive to glutamine depletion (Yuneva et al. 2007). Further, inhibition of glutaminolysis can inhibit a MYC-dependent B-cell lymphoma model and MYCN-amplified neuroblastomas (Le et al. 2012; Qing et al. 2012). MYCN-amplified neuroblastomas were more sensitive to inhibition of glutaminolysis than nonamplified neuroblastomas, strengthening the connection between MYC activity on glutamine dependence (Qing et al. 2012).

Because MYC overexpression drives glutamine utilization and MondoA represses TXNIP expression in the presence of glutamine, it is possible that the high rate of glutaminolysis in MYC overexpressing cells serves to enhance glutamine-dependent repression of TXNIP. The resulting MYC-dependent reduction in TXNIP
MAX- and MLX-Centered Transcription Networks

expression would facilitate aerobic glycolysis to further support cell growth. It is conceivable that the coordinated regulation of TNXIP by MYC and MondoA represents a novel mechanism by which MYC could drive cell growth and macromolecular biosynthesis. At the very least, indirect repression of TXNIP by MYC represents a novel mechanism by which MYC could drive aerobic glycolysis that is independent of its better-documented role in regulating the expression of glycolytic target genes (Kim et al. 2004; Gordan et al. 2007; Dang 2012b). The glutamine-dependent repression of TXNIP we have described is not observed in all cell types (MR Kaadige and DE Ayer, unpubl.), thus it will be of interest to determine whether this regulatory mechanism correlates exclusively with MYC status or whether other regulators also contribute. Triple negative breast cancers have high MYC levels, high rates of aerobic glycolysis, a glycolytic gene signature, and express glutaminase (Chandriani et al. 2009; Foulkes et al. 2010; Palaskas et al. 2011; Horiuchi et al. 2012). Consistent with these findings, triple negative breast cancers are more dependent on glutamine for growth than luminal cancers (Kung et al. 2011). No targeted therapies are currently available for triple negative breast cancers; however, these findings suggest that glutaminase inhibitors, such as BPTES, may have some utility (Robinson et al. 2007).

How restricting glutamine, via glutamine deprivation or inhibition of glutaminolysis, drives apoptosis in a subset of cells types is just becoming clear. In MYCN overexpressing neuroblastoma cells PUMA, NOXA, and TRIB3 are up-regulated following glutamine restriction and work in concert to drive BAX-dependent apoptosis (Qing et al. 2012). Expression of these three effectors is dependent on ATF4, which is selectively translated in a GCN2-dependent manner following glutamine restriction. Although not examined, restricting glutamine would likely increase TXNIP levels in a MondoA-dependent manner. If so, it is possible that TXNIP contributes to apoptosis in glutamine-deprived MYCN-amplified neuroblastoma cells. Whether ATF4 contributes to the activation of TXNIP in the absence of glutamine is 
J.M. O'Shea and D.E. Ayer

unknown. However, ER stress, which activates a number of adaptation pathways that stimulate ATF4 translation, also increases TXNIP expression (Lerner et al. 2012; Oslowski et al. 2012). Thus, it will be interesting to determine whether TXNIP, and potentially ARRDC4, contributes to death of glutamine-addicted tumor cells following glutamine restriction.

\section{CONCLUDING REMARKS}

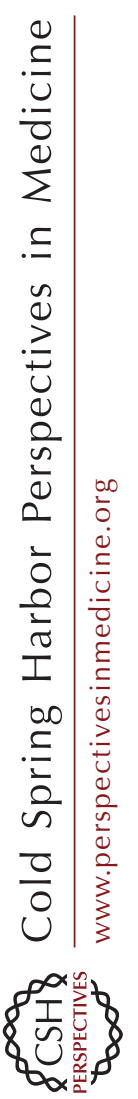

MondoA is a highly conserved member of the bHLHZip family of transcription factors, yet we have only a rudimentary understanding of its biological functions. Many of our suppositions regarding MondoA's role in the cell come from its glucose-induced, direct transcriptional regulation of TXNIP and its paralog ARRDC4. In this light, MondoA appears to be a growth suppressor by negatively regulating glucose uptake and aerobic glycolysis. In addition to blocking glucose uptake, TXNIP has additional growth-suppressive functions (e.g., stabilization of CDK1B and destabilization of HIF1A) (Jeon et al. 2005; Shin et al. 2008). We suggest that TXNIP levels may be repressed by MYC-driven glutaminolysis and we have shown that RAS and/or PI3K activation reduce TXNIP levels (Elgort et al. 2010). MYC, RAS, and PI3K are dysregulated in a wide variety of human cancers and each has clear roles in driving increased glucose utilization. Thus, it is possible that down-regulation of TXNIP by these potent oncogenes is widespread and contributes to the metabolic phenotype of the transformed state. However, the recent demonstration that MondoA may play a progrowth role in B-cell ALL, suggests that its functions are more complicated than this simple model suggests (Wernicke et al. 2012).

Several findings suggest that TXNIP, and likely ARRDC4, are key effectors of MondoA's glucose sensing and adaptation function. Further, the hexose curb requires both MondoA and TXNIP (Stoltzman et al. 2011). However, MondoA knockout MEFs enter quiesence and up-regulate $\mathrm{CDK} 1 \mathrm{~B}$ in response to serum starvation, whereas TXNIP null MEFs do not (MG Elgort and DE Ayer, unpubl.). Thus, MondoA loss does not phenocopy TXNIP loss, implying that MondoA has other important transcriptional targets. Our unpublished global expression experiments reveal $\sim 700$ MondoA-dependent (regulated more than twofold) transcripts in MEFs grown in the presence of glucose and $\sim 700$ MondoA-dependent transcripts in MEFs grown in the absence of glucose. MondoA does enter in the nucleus in the absence of glucose (Peterson et al. 2010), so it is not surprising that one can identify MondoA-dependent genes in glucose-free medium. A challenge in the coming years will be to determine the direct MondoA transcriptome under different nutrient conditions.

MYC and MondoA interact genetically in flies showing a synthetic lethal interaction when the gene dose of each is decreased (Billin and Ayer 2006). Whether similar interactions between MYC and MondoA are extant in human cells is not yet known. Given MYC's dysregulation in cancer and the emerging evidence that the MondoA-TXNIP circuit is growth, and potentially, tumor suppressive, understanding whether and how MYC and MondoA interact is an important question. One can envision a model in which MYC and MondoA coordinate nutrient utilization and availability, respectively. If so, unraveling these nutrient utilization and availability pathways may provide novel targets for the treatment of MYC-dependent tumors.

\section{ACKNOWLEDGMENTS}

We thank members of the Ayer laboratory for their insights. R01GM055668-15, R01DK0844 25-04, and funds from the Huntsman Cancer Foundation support the work in our laboratory. The Cancer Center Support grant P30 CA42014 supports core facility use at the Huntsman Cancer Institute.

\section{REFERENCES}

Arden C, Tudhope SJ, Petrie JL, Al-Oanzi ZH, Cullen KS, Lange AJ, Towle HC, Agius L. 2012. Fructose 2,6-bisphosphate is essential for glucose-regulated gene transcription of glucose-6-phosphatase and other ChREBP target genes in hepatocytes. Biochem J 443: 111-123.

Barretina J, Taylor BS, Banerji S, Ramos AH, Lagos-Quintana M, Decarolis PL, Shah K, Socci ND, Weir BA, Ho A, 
et al. 2010. Subtype-specific genomic alterations define new targets for soft-tissue sarcoma therapy. Nat Genet 42: 715-721.

Basso K, Margolin AA, Stolovitzky G, Klein U, Dalla-Favera R, Califano A. 2005. Reverse engineering of regulatory networks in human B cells. Nat Genet 37: 382-390.

Bhattacharjee A, Richards WG, Staunton J, Li C, Monti S, Vasa P, Ladd C, Beheshti J, Bueno R, Gillette M, et al. 2001. Classification of human lung carcinomas by mRNA expression profiling reveals distinct adenocarcinoma subclasses. Proc Natl Acad Sci 98: 13790-13795.

Billin AN, Ayer DE. 2006. The Mlx network: Evidence for a parallel Max-like transcriptional network that regulates energy metabolism. Curr Top Microbiol Immunol 302: 255-278.

Billin AN, Eilers AL, Coulter KL, Logan JS, Ayer DE. 2000. MondoA, a novel basic helix-loop-helix-leucine zipper transcriptional activator that constitutes a positive branch of a max-like network. Mol Cell Biol 20: 88458854.

Bonome T, Levine DA, Shih J, Randonovich M, Pise-Masison CA, Bogomolniy F, Ozbun L, Brady J, Barrett JC, Boyd J, et al. 2008. A gene signature predicting for survival in suboptimally debulked patients with ovarian cancer. Cancer Res 68: 5478-5486.

Cadenas C, Franckenstein D, Schmidt M, Gehrmann M, Hermes M, Geppert B, Schormann W, Maccoux LJ, Schug M, Schumann A, et al. 2010. Role of thioredoxin reductase 1 and thioredoxin interacting protein in prognosis of breast cancer. Breast Cancer Res 12: R44.

Chandriani S, Frengen E, Cowling VH, Pendergrass SA, Perou CM, Whitfield ML, Cole MD. 2009. A core MYC gene expression signature is prominent in basal-like breast cancer but only partially overlaps the core serum response. PLoS ONE 4: e6693.

Chen J, Saxena G, Mungrue IN, Lusis AJ, Shalev A. 2008a. Thioredoxin-interacting protein: A critical link between glucose toxicity and $\beta$-cell apoptosis. Diabetes 57: $938-$ 944.

Chen JL, Lucas JE, Schroeder T, Mori S, Wu J, Nevins J, Dewhirst M, West M, Chi JT. 2008b. The genomic analysis of lactic acidosis and acidosis response in human cancers. PLoS Genet 4: e1000293.

Chen JL, Merl D, Peterson CW, Wu J, Liu P, Yin H, Muoio DM, Ayer DE, West M, Chi J-T. 2010a. Lactic acidosis triggers starvation response with paradoxical induction of TXNIP through MondoA. PLoS Genet 6: 18.

Chen Z, Yoshihara E, Son A, Matsuo Y, Masutani H, Sugie K, Maeda M, Yodoi J. 2010b. Differential roles of Annexin A1 (ANXA1/lipocortin-1/lipomodulin) and thioredoxin binding protein-2 (TBP-2/VDUP1/TXNIP) in glucocorticoid signaling of HTLV-I-transformed T cells. Immunol Lett 131: 11-18.

Dang CV. 2012a. Links between metabolism and cancer. Genes Dev 26: 877-890.

Dang CV. 2012b. MYC on the path to cancer. Cell 149: 22-35.

Dang CV, Le A, Gao P. 2009. MYC-induced cancer cell energy metabolism and therapeutic opportunities. Clin Cancer Res 15: 6479-6483.
DeBerardinis RJ, Cheng T. 2010. Q's next: The diverse functions of glutamine in metabolism, cell biology and cancer. Oncogene 29: 313-324.

DeBerardinis RJ, Thompson CB. 2012. Cellular metabolism and disease: What do metabolic outliers teach us? Cell 148: $1132-1144$

DeBerardinis RJ, Sayed N, Ditsworth D, Thompson CB. 2008. Brick by brick: Metabolism and tumor cell growth. Curr Opin Genet Dev 18: 54-61.

Delmore JE, Issa GC, Lemieux ME, Rahl PB, Shi J, Jacobs HM, Kastritis E, Gilpatrick T, Paranal RM, Qi J, et al. 2011. BET bromodomain inhibition as a therapeutic strategy to target c-Myc. Cell 146: 904-917.

Dentin R, Tomas-Cobos L, Foufelle F, Leopold J, Girard J, Postic C, Ferre P. 2012. Glucose 6-phosphate, rather than xylulose 5-phosphate, is required for the activation of ChREBP in response to glucose in the liver. $J$ Hepatol 56: 199-209.

Detwiller KY, Fernando NT, Segal NH, Ryeom SW, D'Amore PA, Yoon SS. 2005. Analysis of hypoxia-related gene expression in sarcomas and effect of hypoxia on RNA interference of vascular endothelial cell growth factor A. Cancer Res 65: 5881-5889.

Eilers M, Eisenman RN. 2008. Myc's broad reach. Genes Dev 22: $2755-2766$.

Eilers AL, Sundwall E, Lin M, Sullivan AA, Ayer DE. 2002. A novel heterodimerization domain, CRM1, and 14-3-3 control subcellular localization of the MondoA-Mlx heterocomplex. Mol Cell Biol 22: 8514-8526.

Elgort MG, O'Shea JM, Jiang Y, Ayer DE. 2010. Transcriptional and translational downregulation of Thioredoxin interacting protein is required for metabolic reprogramming during $\mathrm{G}_{1}$. Genes Cancer 1: 893-907.

Filippakopoulos P, Qi J, Picaud S, Shen Y, Smith WB, Fedorov O, Morse EM, Keates T, Hickman TT, Felletar I, et al. 2010. Selective inhibition of BET bromodomains. Nature 468: 1067-1073.

Finak G, Bertos N, Pepin F, Sadekova S, Souleimanova M, Zhao H, Chen H, Omeroglu G, Meterissian S, Omeroglu A, et al. 2008. Stromal gene expression predicts clinical outcome in breast cancer. Nat Med 14: 518-527.

Foulkes WD, Smith IE, Reis-Filho JS. 2010. Triple-negative breast cancer. N Engl J Med 363: 1938-1948.

Gao P, Tchernyshyov I, Chang TC, Lee YS, Kita K, Ochi T, Zeller KI, De Marzo AM, Van Eyk JE, Mendell JT, et al. 2009. c-Myc suppression of miR-23a/b enhances mitochondrial glutaminase expression and glutamine metabolism. Nature 458: 762-765.

Garber ME, Troyanskaya OG, Schluens K, Petersen S, Thaesler Z, Pacyna-Gengelbach M, van de Rijn M, Rosen GD, Perou CM, Whyte RI, et al. 2001. Diversity of gene expression in adenocarcinoma of the lung. Proc Natl Acad Sci 98: $13784-13789$.

Giordano TJ, Au AY, Kuick R, Thomas DG, Rhodes DR, Wilhelm KG Jr, Vinco M, Misek DE, Sanders D, Zhu Z, et al. 2006. Delineation, functional validation, and bioinformatic evaluation of gene expression in thyroid follicular carcinomas with the PAX8-PPARG translocation. Clin Cancer Res 12: 1983-1993. 
J.M. O'Shea and D.E. Ayer

Gordan JD, Thompson CB, Simon MC. 2007. HIF and cMyc: Sibling rivals for control of cancer cell metabolism and proliferation. Cancer Cell 12: 108-113.

Haferlach T, Kohlmann A, Wieczorek L, Basso G, Kronnie GT, Bene MC, De Vos J, Hernandez JM, Hofmann WK, Mills KI, et al. 2010. Clinical utility of microarray-based gene expression profiling in the diagnosis and subclassification of leukemia: Report from the International Microarray Innovations in Leukemia Study Group. J Clin Oncol 28: 2529-2537.

Haslinger C, Schweifer N, Stilgenbauer S, Dohner H, Lichter P, Kraut N, Stratowa C, Abseher R. 2004. Microarray gene expression profiling of B-cell chronic lymphocytic leukemia subgroups defined by genomic aberrations and $\mathrm{VH}$ mutation status. J Clin Oncol 22: 3937-3949.

Havula E, Hietakangas V. 2012. Glucose sensing by ChREBP/MondoA-Mlx transcription factors. Semin Cell Dev Biol 23: 640-647.

Horiuchi D, Kusdra L, Huskey NE, Chandriani S, Lenburg ME, Gonzalez-Angulo AM, Creasman KJ, Bazarov AV, Smyth JW, Davis SE, et al. 2012. MYC pathway activation in triple-negative breast cancer is synthetic lethal with CDK inhibition. J Exp Med 209: 679-696.

Hui ST, Andres AM, Miller AK, Spann NJ, Potter DW, Post NM, Chen AZ, Sachithanantham S, Jung DY, Kim JK, et al. 2008. Txnip balances metabolic and growth signaling via PTEN disulfide reduction. Proc Natl Acad Sci 105: 3921-3926.

Jeon JH, Lee KN, Hwang CY, Kwon KS, You KH, Choi I. 2005. Tumor suppressor VDUP1 increases p27(kipl) stability by inhibiting JAB1. Cancer Res 65: 4485-4489.

Jin HO, Seo SK, Kim YS, Woo SH, Lee KH, Yi JY, Lee SJ, Choe TB, Lee JH, An S, et al. 2011. TXNIP potentiates Redd1-induced mTOR suppression through stabilization of Redd1. Oncogene 30: 3792-3801.

Jones J, Otu H, Spentzos D, Kolia S, Inan M, Beecken WD, Fellbaum C, Gu X, Joseph M, Pantuck AJ, et al. 2005. Gene signatures of progression and metastasis in renal cell cancer. Clin Cancer Res 11: 5730-5739.

Kaadige MR, Looper RE, Kamalanaadhan S, Ayer DE. 2009. Glutamine-dependent anaplerosis dictates glucose uptake and cell growth by regulating MondoA transcriptional activity. Proc Natl Acad Sci 106: 14878-14883.

Kaadige MR, Elgort MG, Ayer DE. 2010. Coordination of glucose and glutamine utilization by an expanded Myc network. Transcription 1: 36-40.

Kim JW, Zeller KI, Wang Y, Jegga AG, Aronow BJ, O’Donnell KA, Dang CV. 2004. Evaluation of myc E-box phylogenetic footprints in glycolytic genes by chromatin immunoprecipitation assays. Mol Cell Biol 24: 5923-5936.

Kim SY, Suh HW, Chung JW, Yoon SR, Choi I. 2007. Diverse functions of VDUP1 in cell proliferation, differentiation, and diseases. Cell Mol Immunol 4: 345-351.

Kung HN, Marks JR, Chi JT. 2011. Glutamine synthetase is a genetic determinant of cell type-specific glutamine independence in breast epithelia. PLoS Genet 7: e1002229.

Le A, Lane AN, Hamaker M, Bose S, Gouw A, Barbi J, Tsukamoto T, Rojas CJ, Slusher BS, Zhang H, et al. 2012. Glucose-independent glutamine metabolism via TCA cycling for proliferation and survival in B cells. Cell Metab 15: 110-121.
Lerner AG, Upton JP, Praveen PV, Ghosh R, Nakagawa Y, Igbaria A, Shen S, Nguyen V, Backes BJ, Heiman M, et al. 2012. IRE $1 \alpha$ induces thioredoxin-interacting protein to activate the NLRP3 inflammasome and promote programmed cell death under irremediable ER stress. Cell Metab 16: 250-264.

Li MV, Chen W, Harmancey RN, Nuotio-Antar AM, Imamura M, Saha P, Taegtmeyer H, Chan L. 2010. Glucose-6phosphate mediates activation of the carbohydrate responsive binding protein (ChREBP). Biochem Biophys Res Commun 395: 395-400.

Lin CY, Loven J, Rahl PB, Paranal RM, Burge CB, Bradner JE, Lee TI, Young RA. 2012. Transcriptional amplification in tumor cells with elevated c-Myc. Cell 151: 56-67.

Ma L, Robinson LN, Towle HC. 2006. ChREBP*Mlx is the principal mediator of glucose-induced gene expression in the liver. J Biol Chem 281: 28721-28730.

McFerrin LG, Atchley WR. 2011. Evolution of the Max and Mlx networks in animals. Genome Biol Evol 3: 915-937.

McFerrin LG, Atchley WR. 2012. A novel N-terminal domain may dictate the glucose response of Mondo proteins. PLoS ONE 7: e34803.

Mertz JA, Conery AR, Bryant BM, Sandy P, Balasubramanian S, Mele DA, Bergeron L, Sims RJ III. 2011. Targeting MYC dependence in cancer by inhibiting BET bromodomains. Proc Natl Acad Sci 108: 16669-16674.

Muoio DM. 2007. TXNIP links redox circuitry to glucose control. Cell Metab 5: 412-414.

Nie Z, Hu G, Wei G, Cui K, Yamane A, Resch W, Wang R, Green DR, Tessarollo L, Casellas R, et al. 2012. c-Myc is a universal amplifier of expressed genes in lymphocytes and embryonic stem cells. Cell 151: 68-79.

Oslowski CM, Hara T, O'Sullivan-Murphy B, Kanekura K, Lu S, Hara M, Ishigaki S, Zhu LJ, Hayashi E, Hui ST, et al. 2012. Thioredoxin-interacting protein mediates ER stress-induced $\beta$ cell death through initiation of the inflammasome. Cell Metab 16: 265-273.

Palaskas N, Larson SM, Schultz N, Komisopoulou E, Wong J, Rohle D, Campos C, Yannuzzi N, Osborne JR, Linkov I, et al. 2011. 18F-Fluorodeoxy-glucose positron emission tomography marks MYC-overexpressing human basallike breast cancers. Cancer Res 71: 5164-5174.

Pardee AB. 1974. A restriction point for control of normal animal cell proliferation. Proc Natl Acad Sci 71: 12861290.

Parikh H, Carlsson E, Chutkow WA, Johansson LE, Storgaard H, Poulsen P, Saxena R, Ladd C, Schulze PC, Mazzini MJ, et al. 2007. TXNIP regulates peripheral glucose metabolism in humans. PLoS Med 4: e158.

Patwari P, Lee RT. 2012. An expanded family of arrestins regulate metabolism. Trends Endocrinol Metab 23: 216222.

Patwari P, Chutkow WA, Cummings K, Verstraeten VL, Lammerding J, Schreiter ER, Lee RT. 2009. Thioredoxin-independent regulation of metabolism by the $\alpha$-arrestin proteins. J Biol Chem 284: 24996-25003.

Peterson CW, Ayer DE. 2011. An extended Myc network contributes to glucose homeostasis in cancer and diabetes. Front Biosci 16: 2206-2223.

Peterson CW, Stoltzman CA, Sighinolfi MP, Han KS, Ayer DE. 2010. Glucose controls nuclear accumulation, pro- 
moter binding, and transcriptional activity of the MondoA-Mlx heterodimer. Mol Cell Biol 30: 2887-2895.

Petrie JL, Al-Oanzi ZH, Arden C, Tudhope SJ, Mann J, Kieswich J, Yaqoob MM, Towle HC, Agius L. 2013. Glucose induces protein targeting to glycogen in hepatocytes by fructose 2,6-bisphosphate-mediated recruitment of MondoA to the promoter. Mol Cell Biol 33: 725-738.

Postic C, Dentin R, Denechaud PD, Girard J. 2007. ChREBP, a transcriptional regulator of glucose and lipid metabolism. Annu Rev Nutr 27: 179-192.

Qing G, Li B, Vu A, Skuli N, Walton ZE, Liu X, Mayes PA, Wise DR, Thompson CB, Maris JM, et al. 2012. ATF4 regulates MYC-mediated neuroblastoma cell death upon glutamine deprivation. Cancer Cell 22: 631-644.

Rauch S, Martin-Serrano J. 2011. Multiple interactions between the ESCRT machinery and arrestin-related proteins: Implications for PPXY-dependent budding. J Virol 85: 3546-3556.

Rhein P, Scheid S, Ratei R, Hagemeier C, Seeger K, Kirschner-Schwabe R, Moericke A, Schrappe M, Spang R, Ludwig WD, et al. 2007. Gene expression shift towards normal B cells, decreased proliferative capacity and distinct surface receptors characterize leukemic blasts persisting during induction therapy in childhood acute lymphoblastic leukemia. Leukemia 21: 897-905.

Robinson MM, McBryant SJ, Tsukamoto T, Rojas C, Ferraris DV, Hamilton SK, Hansen JC, Curthoys NP. 2007. Novel mechanism of inhibition of rat kidney-type glutaminase by bis-2-(5-phenylacetamido-1,2,4-thiadiazol-2-yl)ethyl sulfide (BPTES). Biochem J 406: 407-414.

Roessler S, Jia HL, Budhu A, Forgues M, Ye QH, Lee JS, Thorgeirsson SS, Sun Z, Tang ZY, Qin LX, et al. 2010. A unique metastasis gene signature enables prediction of tumor relapse in early-stage hepatocellular carcinoma patients. Cancer Res 70: 10202-10212.

Sanchez-Carbayo M, Socci ND, Lozano J, Saint F, CordonCardo C. 2006. Defining molecular profiles of poor outcome in patients with invasive bladder cancer using oligonucleotide microarrays. J Clin Oncol 24: 778-789.

Sans CL, Satterwhite DJ, Stoltzman CA, Breen KT, Ayer DE 2006. MondoA-Mlx heterodimers are candidate sensors of cellular energy status: Mitochondrial localization and direct regulation of glycolysis. Mol Cell Biol 26: 48634871 .

Schroder K, Zhou R, Tschopp J. 2010. The NLRP3 inflammasome: A sensor for metabolic danger? Science 327: 296-300.

Shanware NP, Mullen AR, DeBerardinis RJ, Abraham RT. 2011. Glutamine: Pleiotropic roles in tumor growth and stress resistance. J Mol Med (Berl) 89: 229-236.

Shaw RJ, Cantley LC. 2006. Ras, PI3K and mTOR signalling controls tumour cell growth. Nature 441: 424-430.

Sheth SS, Bodnar JS, Ghazalpour A, Thipphavong CK, Tsutsumi S, Tward AD, Demant P, Kodama T, Aburatani H, Lusis AJ. 2006. Hepatocellular carcinoma in Txnip-deficient mice. Oncogene 25: 3528-3536.

Shim H, Dolde C, Lewis BC, Wu CS, Dang G, Jungmann RA, Dalla-Favera R, Dang CV. 1997. c-Myc transactivation of LDH-A: Implications for tumor metabolism and growth. Proc Natl Acad Sci 94: 6658-6663.
MAX- and MLX-Centered Transcription Networks

Shin D, Jeon JH, Jeong M, Suh HW, Kim S, Kim HC, Moon OS, Kim YS, Chung JW, Yoon SR, et al. 2008. VDUP1 mediates nuclear export of HIF1 $\alpha$ via CRM1-dependent pathway. Biochim Biophys Acta 1783: 838-848.

Sloan EJ, Ayer DE. 2010. Myc, Mondo and metabolism. Genes and Cancer 1: 587-596.

Stegmaier K, Ross KN, Colavito SA, O'Malley S, Stockwell BR, Golub TR. 2004. Gene expression-based highthroughput screening (GE-HTS) and application to leukemia differentiation. Nat Genet 36: 257-263.

Stoltzman CA, Peterson CW, Breen KT, Muoio DM, Billin AN, Ayer DE. 2008. Glucose sensing by MondoA:Mlx complexes: A role for hexokinases and direct regulation of thioredoxin-interacting protein expression. Proc Natl Acad Sci 105: 6912-6917.

Stoltzman CA, Kaadige MR, Peterson CW, Ayer DE. 2011. MondoA senses non-glucose sugars: Regulation of thioredoxin-interacting protein (TXNIP) and the hexose transport curb. J Biol Chem 286: 38027-38034.

Sun L, Hui AM, Su Q, Vortmeyer A, Kotliarov Y, Pastorino S, Passaniti A, Menon J, Walling J, Bailey R, et al. 2006. Neuronal and glioma-derived stem cell factor induces angiogenesis within the brain. Cancer Cell 9: 287-300.

Talantov D, Mazumder A, Yu JX, Briggs T, Jiang Y, Backus J, Atkins D, Wang Y. 2005. Novel genes associated with malignant melanoma but not benign melanocytic lesions. Clin Cancer Res 11: 7234-7242.

Talbot SG, Estilo C, Maghami E, Sarkaria IS, Pham DK, Ocharoenrat P, Socci ND, Ngai I, Carlson D, Ghossein R, et al. 2005. Gene expression profiling allows distinction between primary and metastatic squamous cell carcinomas in the lung. Cancer Res 65: 3063-3071.

Tomlins SA, Mehra R, Rhodes DR, Cao X, Wang L, Dhanasekaran SM, Kalyana-Sundaram S, Wei JT, Rubin MA, Pienta KJ, et al. 2007. Integrative molecular concept modeling of prostate cancer progression. Nat Genet 39: $41-51$.

Uyeda K, Repa JJ. 2006. Carbohydrate response element binding protein, ChREBP, a transcription factor coupling hepatic glucose utilization and lipid synthesis. Cell Metab 4: $107-110$.

Vander Heiden MG, Cantley LC, Thompson CB. 2009. Understanding the Warburg effect: The metabolic requirements of cell proliferation. Science 324: 1029-1033.

Wallace TA, Prueitt RL, Yi M, Howe TM, Gillespie JW, Yfantis HG, Stephens RM, Caporaso NE, Loffredo CA, Ambs S. 2008. Tumor immunobiological differences in prostate cancer between African-American and European-American men. Cancer Res 68: 927-936.

Wang R, Green DR. 2012. Metabolic checkpoints in activated T cells. Nat Immunol 13: 907-915.

Wang Z, Rong YP, Malone MH, Davis MC, Zhong F, Distelhorst CW. 2006. Thioredoxin-interacting protein (txnip) is a glucocorticoid-regulated primary response gene involved in mediating glucocorticoid-induced apoptosis. Oncogene 25: 1903-1913.

Ward PS, Thompson CB. 2012. Metabolic reprogramming: A cancer hallmark even Warburg did not anticipate. Cancer Cell 21: 297-308.

Wernicke CM, Richter GH, Beinvogl BC, Plehm S, Schlitter AM, Bandapalli OR, Prazeres da Costa O, Hattenhorst 
J.M. O'Shea and D.E. Ayer

UE, Volkmer I, Staege MS, et al. 2012. MondoA is highly overexpressed in acute lymphoblastic leukemia cells and modulates their metabolism, differentiation and survival. Leuk Res 36: 1185-1192.

Wise DR, DeBerardinis RJ, Mancuso A, Sayed N, Zhang XY, Pfeiffer HK, Nissim I, Daikhin E, Yudkoff M, McMahon SB, et al. 2008. Myc regulates a transcriptional program that stimulates mitochondrial glutaminolysis and leads to glutamine addiction. Proc Natl Acad Sci 105: 1878218787.

Wu N, Zheng B, Shaywitz A, Dragon Y, Tower C, Bellinger G, Chen C-H, Wen J, Asara JM, McGraw TE, et al. 2013. AMPK-dependent degradation of TXNIP upon energy stress leads to enhanced glucose uptake via GLUT1. Mol Cell 49: 1-9.
Yun J, Johnson JL, Hanigan CL, Locasale JW. 2012. Interactions between epigenetics and metabolism in cancers. Front Oncol 2: 163.

Yuneva M, Zamboni N, Oefner P, Sachidanandam R, Lazebnik Y. 2007. Deficiency in glutamine but not glucose induces MYC-dependent apoptosis in human cells. J Cell Biol 178: 93-105.

Zhou J, Chng WJ. 2012. Roles of thioredoxin binding protein (TXNIP) in oxidative stress, apoptosis and cancer Mitochondrion 13: 163-169.

Zhou J, Yu Q, Chng WJ. 2011. TXNIP (VDUP-1, TBP-2): A major redox regulator commonly suppressed in cancer by epigenetic mechanisms. Int J Biochem Cell Biol 43: $1668-$ 1673. 


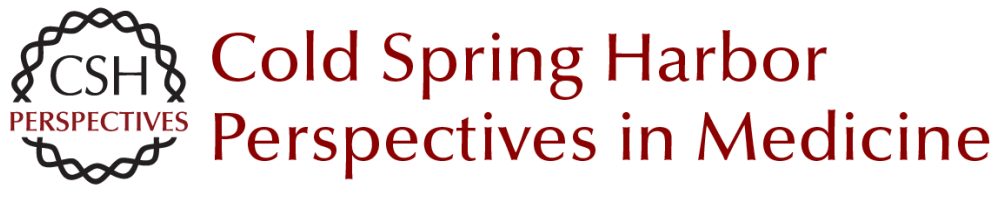

\section{Coordination of Nutrient Availability and Utilization by MAX- and MLX-Centered Transcription Networks}

John M. O'Shea and Donald E. Ayer

Cold Spring Harb Perspect Med 2013; doi: 10.1101/cshperspect.a014258

Subject Collection MYC and the Pathway to Cancer

MYC Cofactors: Molecular Switches Controlling

Diverse Biological Outcomes Stephen R. Hann

MYC Association with Cancer Risk and a New Model of MYC-Mediated Repression Michael D. Cole

MYC and the Art of MicroRNA Maintenance James N. Psathas and Andrei Thomas-Tikhonenko

MYC Activation Is a Hallmark of Cancer Initiation and Maintenance Meital Gabay, Yulin Li and Dean W. Felsher

MYC and Mitochondrial Biogenesis Fionnuala Morrish and David Hockenbery

Synthetic Lethal Screens as a Means to Understand and Treat MYC-Driven Cancers Silvia Cermelli, In Sock Jang, Brady Bernard, et al.

An Overview of MYC and Its Interactome Maralice Conacci-Sorrell, Lisa McFerrin and Robert N. Eisenman

Socializing with MYC: Cell Competition in Development and as a Model for Premalignant Cancer

Laura A. Johnston
MYC and the Control of Apoptosis Steven B. McMahon

Therapeutic Strategies to Inhibit MYC Michael R. McKeown and James E. Bradner

MYC and the Control of DNA Replication David Dominguez-Sola and Jean Gautier

MYC Regulation of Cell Growth through Control of Transcription by RNA Polymerases I and III Kirsteen J. Campbell and Robert J. White

MYC Degradation Amy S. Farrell and Rosalie C. Sears

MYC and Transcription Elongation Peter B. Rahl and Richard A. Young

c-MYC-Induced Genomic Instability Alexandra Kuzyk and Sabine Mai

Oncogenic Mechanisms in Burkitt Lymphoma Roland Schmitz, Michele Ceribelli, Stefania Pittaluga, et al.

For additional articles in this collection, see http://perspectivesinmedicine.cshlp.org/cgi/collection/ 